\title{
TENSE IN ADJUnCTS PART 2: TEMPORAL AdVERBIAL Clauses
}

\section{RECAPITULATION}

Part I of this article treats tense in relative clauses (RCs) in English, Russian and Japanese. The temporal centre in RCs can always be $\mathrm{Tpro}_{\mathrm{i}}$, and sometimes it has to be $\mathrm{Tpro}_{\mathrm{i}}$.

1. In SOT languages such as English, the Tense in the RC is bound in RClwollconfigurations, i.e., we find a $\mathrm{Tpro}_{i}$ bound by woll. The licensing of the morphological tense in the RC is non-local in these cases. In most other constructions, the RC-Tense is deictic and tense licensing is local.

2. In Russian, a non-SOT language, the RC-Tense is bound in FUT Rus $_{\mathrm{P}} \mathrm{PAST}$ configurations. In other configurations, the RC-Tense is deictic. Tense licensing is local.

3. In Japanese, another non-SOT language, the RC-Tense is bound in PRES Jap $_{P} \mathrm{PAST}$ configurations. In other configurations, the RC-Tense is deictic. Tense licensing is local.

In Part 2 we will investigate Tense in temporal adverbial clauses (TACs) headed by after, before and when.

\section{Tense Distribution In TACS}

We start with a survey of the tense distribution in the languages investigated.

English: (Stump, 1985), p. 124

a. John will leave before Mary sings/ ${ }^{?}$ will sing

b. John will leave after Mary sings ${ }^{? ?}$ will sing.

c. John left before/after Mary sang.

Under will, we find present tense in the TAC. When the main tense is Past, the subordinate tense is Past as well.

In German, the main tense and subordinate tense are the same in the beforeconstruction. In after-constructions, we need a Present Perfect (or Pluperfect) in the adjunct:

(2) German 
a. Hans geht/wird gehen, bevor Maria singt/singen wird Hans leaves/will leave, before Mary sings/sing will

b. Hans ging/ist gegangen, bevor Maria sang/gesungen \{hat/hatte Hans left/has left, before Mary sang/sung \{has/had\}

c. Hans wird den Saal verlassen, nachdem Maria gesungen hat/? sang/*singt Hans will the room leave, after Maria has sung/? sang/*sings

French can be like German with the difference that the adjunct clause is in the subjunctive, cf. the French counterpart of Stump's sentence (1b):

(3) French

Jean va partir après que Marie ait ${ }^{\text {pres,subj }}$ chantéperf.part $/ *$ chante $\mathrm{p}^{\text {pres,subj }}$

John will leave after that Mary have sung/*sings

In Russian, the main tense and adjunct tense are the same:

(4) Russian

a. Vanja uedet ${ }^{\text {fut,pfv }}$ do/posle togo, kak Masha uedet ${ }^{\text {fut,pfv }}$. John will-leave before/after this how Mary will-leave

b. Vanja uekhal ${ }^{\text {past,pfv }}$ do/posle togo, kak Masha uekhala ${ }^{\text {past,pfv }}$. John left before/after this how Mary left

In Japanese, regardless of the matrix tense, the tense is Past in after-adjuncts and Present in before-adjuncts (examples from (Kusumoto, 1999), chap. 3)):

Japanese

a. [Junko-ga kuru ${ }^{\text {pres }} / *$ kita $^{\text {past }}$ maeni] Satoshi-wa kaetta ${ }^{\text {past }}$

[J-nom comes/*came before] S-top left

'Satoshi left before Junko came'

b. [Junko-ga kita ${ }^{\text {past }} / *$ kuru $^{\text {pres }}$ atoni] Satoshi-wa kaeru ${ }^{\text {pres }}$ daroo

[J-nom came/*comes after] S-top leaves probably

'Satoshi will leave after Junko comes'

English when-adjuncts show Stump's pattern as well. We find present tense under will, but Past under Past.

a. John will leave when Mary sings $/{ }^{? ?}$ will sing

b. John left when Mary sang.

Russian has tense harmony between the matrix and adjunct: 


$$
\begin{aligned}
& \text { Alla uedet }{ }^{\text {fut,pfv }} \text { (uekhala }{ }^{\text {past,pfv }} \text { ), kogda Vova uedet }{ }^{\text {fut,pfv }} \text { (uekhal }{ }^{\text {past,pfv }} \text { ). } \\
& \text { Alla will-leave (left) when Vova will-leave (left) }
\end{aligned}
$$

In Japanese, the main tense and adjunct tense can be the same, but we can also have the configuration Pres\Past with the same meaning as Past\Past:

$$
\text { [Satoshi-ga kita }{ }^{\text {past }} \text { toki] Junko-wa heya-ni ita }{ }^{\text {past }}
$$

(Kusumoto, 1999), p. 221

[S-nom come when] J-top room-in be

'Junko was in her room when Satoshi came'

$$
\begin{aligned}
& \text { [heya-de neteiru }^{\text {pres }} \text { tokini] Junko-ga tazunete-ki-ta }{ }^{\text {past }} \\
& \text { [room-at sleep-teiru when] J-top visit-come } \\
& \text { 'Junko visited me when I was sleeping in my room' }
\end{aligned}
$$

(Kusumoto, 1999), p. 222

Russian tense behaves as one would expect in a non-SOT language: the adjunct tense is independent from the matrix tense. Japanese is basically like Russian. The Pres $\backslash$ Pastconfiguration will follow from the existence of a relative Present in Japanese. We will see, however, that Japanese Tense under beforelafter is not deictic; additional data will show that the Tense in these adjuncts has a vacuous T-centre. Looking at the English data, it is striking that we find a shifted present tense under will, i.e. precisely in the structure where we found a shifted present (or past tense) in English RCs. A natural guess is therefore that the present in these TACs is licensed by a Tpro ${ }_{i}$ bound by will.

\section{THE PROGRAM}

First we will say what before and after mean. We will see that these conjunctions embed a definite term that is formed from a covert definite operator plus a relative clause. This allows us to apply the methods used in Part 1 to license the tense in the embedded RC. The when-adjunct will turn out to be a RC without determiner. This will require a somewhat different account. We treat before and after separately from when because their syntax is different.

Apart from the temporal distribution illustrated above, we have to deal with three more problems.

1. We have to account for an ambiguity observed in (Geis, 1970):

Olga came after/before Harry told her to come. 


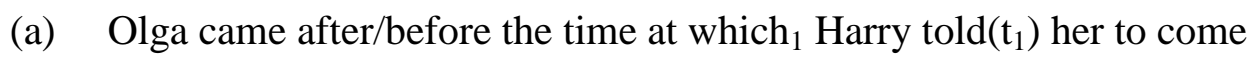

(b) Olga came after/before the time at which $\mathrm{H}_{1}$ Harry told her to come $\left(\mathrm{t}_{1}\right)$

The adjunct in (a) speaks about the time of Harry's telling, the adjunct in (b) speaks about the time of Olga's coming.

2. before-adjuncts face the problem of veridicality, i.e. the event described in the adjunct need not occur:

(11) Mozart died before he finished the requiem.

3. before-adjuncts license negative polarity items (NPIs), after-adjuncts do not.

a. Cleo left before anybody else left.

b. *Cleo left after anybody else left.

\section{BEFORE- AND AFTER-ADJUNCTS IN ENGLISH}

\subsection{What after and before mean}

Classical analyses following (Anscombe, 1964) treat the conjunctions as generalized quantifiers over times; before as a universal quantifier and after as an existential quantifier of type (it)(it,t).

(13) Anscombe's proposal in modern notation

a. [[ before $\rrbracket(B)(A)=1$ iff $(\exists t)\left[A(t) \&\left(\forall t^{\prime}\right)\left[B\left(t^{\prime}\right) \rightarrow t\right.\right.$ is before $\left.\left.t^{\prime}\right]\right]$

b. $\left[\operatorname{after} \rrbracket(B)(A)=1\right.$ iff $(\exists t)\left[A(t) \&\left(\exists t^{\prime}\right)\left[B\left(t^{\prime}\right) \& t\right.\right.$ is after $\left.\left.t^{\prime}\right]\right]$

Disregarding the problem that this semantics leaves no place for plugging in semantic tense, the asymmetry of the two meanings seems to account for the non-veridicality of before and the distribution of NPIs. The non-veridicality follows from the fact that the complement B of before is the antecedent of a material conditional: if it is false, the entire conditional is true. So the sentence in (11) is true because Mozart finished the requiem is false. The licensing of NPIs in before-adjuncts is explained as well because an NPI is licensed if it occurs in a downward entailing (DE) context, and antecedents of conditionals are DE (cf. (Ladusaw, 1979).

(Beaver and Condoravdi, 2003) - henceforth B\&C - observe that Anscombe sometimes predicts strange truth conditions. For instance, the following sentence comes out true, even though David didn't participate in the Olympics and his athletic abilities are close to zero: 
(14) David ate lots of ketchup before he made a clean sweep of the gold medals in the Sidney Olympics.

The way towards a more promising account starts from the observation that in examples involving only one sentence there is no way to treat after and before as sentence conjunctions:

Mary left after/before 5.

In this use after/before simply denote relations between two times:
a. $\llbracket \operatorname{after}_{i(i t)} \rrbracket=\lambda w \lambda t \lambda t^{\prime} . t^{\prime}>t$
b. $\llbracket$ before $\left._{i(i t)}\right]=\lambda w \lambda t \lambda t^{\prime} . t^{\prime}<t$

A reasonable LF for (15) is therefore the following:

$$
\begin{aligned}
& \operatorname{PAST}(\mathrm{n}) \lambda_{1}\left[\mathrm{vp}\left[\mathrm{vP} \text { TPRO } \lambda_{2} \operatorname{Mary} \operatorname{leave}\left(\mathrm{t}_{2}\right)\right]\left[\mathrm{PP} \operatorname{after} / \text { before 5]](} \mathrm{t}_{1}\right)\right. \\
& =\left(\exists \mathrm{t}_{1}<\mathrm{s} *\right) \text { Mary leave }\left(\mathrm{t}_{1}\right) \& \mathrm{t}_{1}>/<5
\end{aligned}
$$

Let us see how the truth-condition is computed. The VP and the PP are combined by Predicate Modification, which requires that the two phrases are of the same type. Since the time argument $t_{2}$ is the first in our approach, we have to $\lambda$-bind it in order to unify the types, i.e., we apply TPRO-movement. Ignoring the world parameter, the meaning of the complex VP [VP [VP $\lambda_{2}$ Mary leave $\left.\left(t_{2}\right)\right]$ [PP after/before 5]] is then [ $\lambda \mathrm{t}$ Mary leaves at $\left.\mathrm{t} \& \mathrm{t}>/<5\right]$. This meaning is applied to the variable $t_{1}$, which is ultimately bound by PAST(n). The result is that PAST(n) binds both the time variable of leave and the "subject"-variable of after/before. The somewhat complicated composition of the VP with the after/before-PP is an outcome of our logical type i(et) for the verb. To facilitate readability, we will use the following abbreviation:

$$
\operatorname{PAST}(n) \lambda_{1}\left[\mathrm { vP } [ \mathrm { VP } \operatorname { M a r y } \operatorname { l e a v e } ( \mathrm { t } _ { 1 } ) ] \& \left[\mathrm{PP}_{\mathrm{1}}\right.\right. \text { after/before 5]] }
$$

This notation makes it obvious that PAST(n) binds both the time variable of leave and the subject variable of after/before. (von Stechow, 2002) and (Beaver and Condoravdi, 2003) adopt the simple meanings given in (16) also in TACs. This is what we will do next.

\subsection{The Composition of after/before-Clauses}

Consider the sentence

$$
\text { John left after Mary left. }
$$

We want to analyze the TAC after Mary left with the meaning for after in (16). We seem 
to face a type mismatch: after requires an object of type $i$ but Mary left is of type $t$. Suppose now that the complement of after is more complicated, namely THE TIME AT WHICH Mary left, where the material in capitals is covert. Such a move will make the complement of after of type i. Let us have a closer look at the syntax under this perspective. The definite term contains a temporal RC, i.e., the syntax has the following form:

$$
\begin{aligned}
& \text { a. SO: THE TIME [СР } \left.[\text { AT WHICH }]_{1}\left[\mathrm{C}\left[\mathrm{TP} P A S T\left(n / \operatorname{Tpro}_{\mathrm{i}}\right) \lambda_{2} \operatorname{Mary} \operatorname{left}\left(\mathrm{t}_{2}\right) \mathrm{t}_{1}\right]\right]\right] \\
& \text { b. LF: THE TIME }\left[\mathrm{CP} \mathrm{WHICH}_{1}\left[\mathrm{C}\left[\mathrm{TP} P A S T\left(n / \operatorname{Tpro}_{\mathrm{i}}\right) \lambda_{2} \operatorname{Mary} \operatorname{left}\left(\mathrm{t}_{2}\right)\left[\mathrm{AT} \mathrm{t}_{1}\right]\right]\right]\right. \\
& \quad=\text { the time } \mathrm{t}_{1} \cdot\left(\exists \mathrm{t}_{2}<\mathrm{s} * / \mathrm{t}_{\mathrm{i}}\right) \operatorname{Mary} \operatorname{leave}\left(\mathrm{t}_{2}\right) \& \mathrm{t}_{2}=\mathrm{t}_{1}
\end{aligned}
$$

At Spell-Out, the preposition at is pied-piped with the wh-word, but at LF it is reconstructed. In English TACs, the temporal wh-PP is covert and therefore represented in capitals. In Russian the wh-PP is overt. In order to obtain the meaning indicated above, we assume the following meaning for at/AT:

$$
\llbracket \mathbf{a t} / \mathrm{AT}_{\mathrm{i}(\mathrm{it})} \rrbracket=\lambda \mathrm{w} \lambda \mathrm{t} \lambda \mathrm{t}^{\prime} \cdot \mathrm{t}^{\prime}=\mathrm{t}\left(\text { or: } \mathrm{t}^{\prime} \subseteq \mathrm{t}\right)
$$

One problem remains. We have to say what "THE TIME..." means. There are many times at which Mary left. We follow the proposal by B\&C, according to which the definite description means "the earliest time...". With the covert operator EARLIEST the official LF for the entire TAC is this:

$$
\begin{aligned}
& \text { after [EARLIEST }{ }_{\mathrm{CP}} \mathrm{WH}_{1}\left[{ } _ { \mathrm { TP } } \mathrm { PAST } ( \mathrm { n } / \mathrm { Tpro } _ { \mathrm { i } } ) \lambda _ { 2 } [ \mathrm { vp } _ { \mathrm { vp } } \lambda _ { 3 } \operatorname { M a r y } \operatorname { l e a v e } ( \mathrm { t } _ { 3 } ) ] \left[{ }_{\mathrm{PP}} \mathrm{AT}\right.\right. \\
& \left.\left.\left.\left.\left.\mathrm{t}_{1}\right]\right]\left(\mathrm{t}_{2}\right)\right]\right]\right] \\
& =\operatorname{after}\left[\text { EARLIEST } \left[\mathrm { CP } _ { \mathrm { PH } } \mathrm { WTP } _ { 1 } \mathrm { PAST } ( \mathrm { n } / \mathrm { Tpro } _ { \mathrm { i } } ) \lambda _ { 2 } \left[\mathrm { vP } [ \mathrm { vP } \operatorname { M a r y } \text { leave } ( \mathrm { t } _ { 2 } ) ] \& \left[\mathrm{PP}_{2}\right.\right.\right.\right. \\
& \left.\left.\left.\left.\left.\mathrm{AT}_{1}\right]\right]\right]\right]\right] \\
& =\lambda \mathrm{t} . \mathrm{t}>\text { the earliest time } \mathrm{t}_{1} .\left(\exists \mathrm{t}_{2}<\mathrm{s} * / \mathrm{t}_{\mathrm{i}}\right) \operatorname{Mary} \operatorname{left}\left(\mathrm{t}_{2}\right) \& \mathrm{t}_{2}=\mathrm{t}_{1}
\end{aligned}
$$

The second line uses the writing convention we introduced in (18). The representation leaves it open whether the tense in the adjunct is deictic or anaphoric. The meaning of EARLIEST is this:

$$
\begin{aligned}
& \text { [[EARLIEST }{ }_{(\mathrm{it}) \mathrm{t}} \rrbracket=\lambda \mathrm{P}_{\mathrm{it}} \text {. the earliest time } \mathrm{t} \text { such that } \mathrm{P}(\mathrm{t}) \\
& =\text { the } \mathrm{t} \text {, such that } \mathrm{P}(\mathrm{t}) \&\left(\forall \mathrm{t}^{\prime}\right)\left[\mathrm{t}^{\prime} \neq \mathrm{t} \& \mathrm{P}\left(\mathrm{t}^{\prime}\right) \rightarrow \mathrm{t}<\mathrm{t}^{\prime}\right]
\end{aligned}
$$

(B\&C include a modal component quantifying over possible futures into the operator; that makes the operator very complex. We return to this later.). A more modularized approach should decompose the operator into the + earliest, where the would be of type (it)i and earliest would be of type (it)(it), but we leave it at the fused version (23). 


\section{3. after/before under Past}

Now we can give an analysis of (19). The simplest version is this:

$$
\begin{aligned}
& \text { n } \lambda_{1} \operatorname{PAST}\left(\mathrm{t}_{1}\right) \lambda_{2} \text { John leave }\left(\mathrm{t}_{2}\right) \& \\
& \left.t_{2} \text { after EARLIEST } \mathrm{WH}_{3} \text { PAST(n/Tpro }{ }_{1}\right) \lambda_{4} \text { Mary leave }\left(\mathrm{t}_{4}\right) \& \mathrm{t}_{4} \mathrm{AT}_{3} \\
& \text { i-past__u-past } \\
& =\left(\exists \mathrm{t}_{2}<\mathrm{s}^{*}\right) \text { John left }\left(\mathrm{t}_{2}\right) \\
& \& \mathrm{t}_{2}>\text { the earliest time } \mathrm{t}_{3} .\left(\exists \mathrm{t}_{4}<\mathrm{s} *\right) \text { Mary left }\left(\mathrm{t}_{4}\right) \& \mathrm{t}_{4}=\mathrm{t}_{3}
\end{aligned}
$$

The adjunct tense is deictic and the tense in the adjunct is checked by the local PAST. (Recall the writing convention for the use of " $\&$ " from section 4.1.) In sections 4.7 and 4.8 we will see that a proper LF is presumably more complicated.

The following sentence is predicted to be unacceptable:

*John left after Mary leaves.

To license the embedded present, a feature [u-pres] must come from a local $\mathrm{n}$ or from the matrix $\mathrm{n}$. In both cases we get an inconsistent interpretation.

Veridical before-adjuncts under Past have the same analysis. Here is an example:

$$
\text { John left before Mary came. }
$$$$
\left(\exists \mathrm{t}_{2}<\mathrm{s} *\right) \operatorname{John} \operatorname{left}\left(\mathrm{t}_{2}\right)
$$

$\& \mathrm{t}_{2}<$ the earliest time $\mathrm{t}_{3} .\left(\exists \mathrm{t}_{4}<\mathrm{s}^{*}\right)$ Mary came $\left(\mathrm{t}_{4}\right) \& \mathrm{t}_{4}=\mathrm{t}_{3}$

Take the analysis in (24), replace after by before and calculate the truth-condition.

\subsection{NPIs in before-Adjuncts}

Here is a comment on why B\&C's analysis accounts for the licensing of NPIs in beforecomplements but not in after-complements: the former are downward entailing (= DE) contexts, the latter are not. The following intuitive argument involving a progressive ("stativizer") makes this clear:

(27) Cleo left before David was singing entails Cleo left before David was singing loudly

(28) Cleo left after David was singing doesn't entail Cleo left after David was singing loudly

So we can make the before-complement stronger preserving the truth, but we cannot do that 
with an after-complement. This shows that before creates a DE-context and thus licenses NPIs.

\subsection{Geis'Ambiguity}

Let us consider Geis' ambiguity next. As one might expect, the two readings are explained by two different locations of the AT-PP. Here is the upper construal.

(29) Olga came before (the time) wh $\mathrm{h}_{1}$ Harry told her at $\mathrm{t}_{1}$ to come.

n $\lambda_{1} \operatorname{PAST}\left(\mathrm{t}_{1}\right) \lambda_{2}$ Olga come $\left(\mathrm{t}_{2}\right) \& \mathrm{t}_{2}$ before

EARLIEST WH $\mathrm{H}_{3} \operatorname{PAST}(\mathrm{n}) \lambda_{4} \mathrm{t}_{4} \mathrm{AT}_{3} \&$ Harry tell-her $\left(\mathrm{t}_{4}\right) \lambda_{5}$ to come $\left(\mathrm{t}_{5}\right)$

$=\lambda \mathrm{w} \cdot\left(\exists \mathrm{t}_{2}<\mathrm{s}^{*}\right)$ Olga came $\left(\mathrm{w}, \mathrm{t}_{2}\right) \& \mathrm{t}_{2}<$ the earliest $\mathrm{t}_{3} \cdot\left(\exists \mathrm{t}_{4}<\mathrm{s}^{*}\right) \mathrm{t}_{4}=\mathrm{t}_{3} \&$ Harry tell$\operatorname{her}\left(\mathrm{w}, \mathrm{t}_{4}\right) \lambda \mathrm{w}^{\prime} \lambda \mathrm{t}_{5}$. to come $\left(\mathrm{w}^{\prime}, \mathrm{t}_{5}\right)$

And here is the lower construal:

(30) Olga came before the time $\mathrm{wh}_{1}$ Harry told her to come at $\mathrm{t}_{1}$.

n $\lambda_{1} \operatorname{PAST}\left(\mathrm{t}_{1}\right) \lambda_{2}$ Olga come $\left(\mathrm{t}_{2}\right) \& \mathrm{t}_{2}$ before

EARLIEST WH $\mathrm{WHAST}_{3}$ P) $\lambda_{4}$ Harry tell-her $\left(\mathrm{t}_{4}\right) \lambda_{5}$ to come $\left(\mathrm{t}_{5}\right) \& \mathrm{t}_{5} \mathrm{AT}_{3}$

$=\lambda \mathrm{w} .\left(\exists \mathrm{t}_{2}<\mathrm{s}^{*}\right)$ Olga came $\left(\mathrm{w}, \mathrm{t}_{2}\right) \& \mathrm{t}_{2}<$ the earliest $\mathrm{t}_{3} \cdot\left(\exists \mathrm{t}_{4}<\mathrm{s}^{*}\right)$ Harry told-her $\left(\mathrm{w}, \mathrm{t}_{4}\right)$

$\lambda w^{\prime} \lambda t_{5}$. to come $\left(w^{\prime}, t_{5}\right) \& t_{5}=t_{3}$

The licensing of the morphological tenses in these structures is done by a local PAST in each case.

\subsection{Non-Veridical before-Adjuncts}

There are a number of proposals in the literature according to which before has to be modalized (Ogihara, 1996), (Kusumoto, 1999), (Beaver and Condoravdi, 2003). We assume a silent COULD in the before-adjunct. This can be regarded as a decomposed version of B\&C's proposal, which fuses the EARLIEST with a (complicated) modal. We propose the following LF for (11):

$$
\mathrm{n} \lambda_{1} \operatorname{PAST}\left(\mathrm{t}_{1}\right) \lambda_{2} \operatorname{Mozart} \operatorname{die}\left(\mathrm{t}_{2}\right) \& \mathrm{t}_{2} \text { before }
$$


EARLIEST WH $\left.\mathrm{WHST}_{3} \operatorname{PA}\right) \lambda_{4} \mathrm{t}_{4} \mathrm{AT}_{3} \& \operatorname{COULD}_{\mathrm{R}}\left(\mathrm{t}_{4}\right) \lambda_{5} \mathrm{FUT}\left(\mathrm{t}_{5}\right) \lambda_{6}$ he finish $\left(\mathrm{t}_{6}\right)$ the i-past u-past u-past

requiem.

$=\lambda \mathrm{w} \cdot\left(\exists \mathrm{t}_{2}<\mathrm{s}^{*}\right) \operatorname{Mozart} \operatorname{die}\left(\mathrm{w}, \mathrm{t}_{2}\right) \& \mathrm{t}_{2}<$ the earliest $\mathrm{t}_{3} \cdot\left(\exists \mathrm{t}_{4}<\mathrm{s}^{*}\right) \mathrm{t}_{4}=\mathrm{t}_{3} \&$

$\left(\exists w^{\prime}\right)\left[w R_{4} w^{\prime} \&\left(\exists t_{6}>t_{4}\right)\right.$ he finish $\left(w^{\prime}, t_{6}\right)$ the requiem]

Thus, COULD has the following (standard) meaning:

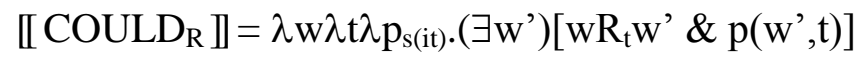

The covert modal COULD doesn't block feature transmission. Hence the past morphology of finish is licensed by the local PAST via feature transmission under binding. The covert FUT under the modal is not an ad hoc move; it is found in many modal constructions (von Stechow, 2005).

\section{7. before/after under will}

We have to find licensers for the present tense in the adjunct clause of the "Stumpsentences" (1a) and (1b). Pursuing the deictic approach, a reasonable LF for (1a) is this:

n $\lambda_{1}$ woll $\left(\mathrm{t}_{1}\right) \lambda_{2}$ John leave $\left(\mathrm{t}_{2}\right) \&$

$\mathrm{t}_{2}$ before EARLIEST $\mathrm{WH}_{3} n \lambda_{5} \underline{\mathrm{FUT}}\left(\mathrm{t}_{5}\right) \lambda_{4} \operatorname{Mary} \operatorname{sing}\left(\mathrm{t}_{4}\right) \& \mathrm{t}_{4} \mathrm{AT}_{3}$ i-pres__ u-pres

$\left(\exists t_{2}>s^{*}\right)$ John leave $\left(t_{2}\right) \& t_{2}<$ the earliest $t_{3} \cdot\left(\exists t_{5}>s^{*}\right)$ Mary $\operatorname{sing}\left(t_{5}\right) \& t_{5}=t_{3}$

The LF would be inconsistent without the pragmatic addition of a covert FUT in the adjunct. The LF for (1b) is the same except that before is replaced by after.

So a deictic analysis of before/after-adjuncts is possible with a bit of pragmatic adjustment. This analysis would be compatible with (Kusumoto, 1999)'s claim that the adjunct tense in afterlbefore-adjuncts is always independent, i.e., deictic. The drawback of the analysis is that it offers no explanation for the parallel behaviour of RCs in the Abusch/Ogihara examples from Part I and Stump's sentences. In both cases, an embedded RC has present tense under will and past tense under would. (A TAC illustrating the latter claim is: Gregory said John would leave after/before Mary came.)

Here is a LF for the beforelwoll construction with a bound anaphoric adjunct tense:

$$
\text { n } \lambda_{1} \text { woll }\left(\mathrm{t}_{1}\right) \lambda_{2} \text { John leave }\left(\mathrm{t}_{2}\right) \&
$$




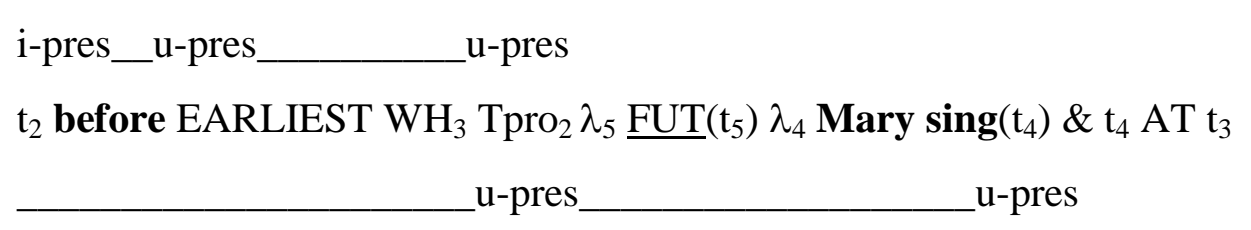

$\left(\exists t_{2}>s^{*}\right)$ John leave $\left(t_{2}\right) \& t_{2}<$ the earliest $t_{3} \cdot\left(\exists t_{4}>t_{2}\right)$ Mary $\operatorname{sing}\left(t_{4}\right) \& t_{4}=t_{3}$

This LF differs from the previous one by having a Tpro 2 bound by woll instead of $n$ as the adjunct tense. This time, however, the embedded [u-pres] is transmitted from the matrix Pres. The bound version of afterlwoll needs a covert relative HAVE (or PAST) in the adjunct to be consistent:

(35) John will leave after Mary sings.

n $\lambda_{1} \operatorname{woll}\left(\mathrm{t}_{1}\right) \lambda_{2}$ John leave $\left(\mathrm{t}_{2}\right) \&$

$\mathrm{t}_{2}$ after EARLIEST $\mathrm{WH}_{3} \mathrm{Tpro}_{2} \lambda_{5} \underline{\operatorname{HAVE}\left(\mathrm{t}_{5}\right)} \lambda_{4} \operatorname{Mary} \operatorname{sing}\left(\mathrm{t}_{4}\right) \& \mathrm{t}_{4} \mathrm{AT}_{3}$

$=\left(\exists t_{2}>s^{*}\right)$ John leave $\left(t_{2}\right) \& t_{2}>$ the earliest time $t_{3} .\left(\exists t_{4}<t_{2}\right)$ Mary $\operatorname{sing}\left(t_{4}\right) \& t_{4}=t_{3}$

Recall that the deictic variant for this sentence has a covert FUT instead of HAVE. Thus, both strategies need some pragmatic accommodation; a covert relative tense or auxiliary in the adjunct. The parallelism between RCs and TACs favours the anaphoric strategy.

There is some cross-linguistic evidence supporting this analysis. Recall the data from German and French in (2) and (3), where we need a perfect auxiliary in the afteradjunct. The perfect auxiliaries haben/avoir occur exactly at the position where we inserted the covert HAVE in (35). It is hard to see how an analysis of German/French could be compatible with a deictic account of the adjunct.

The account raises the question of why will $/ w i l l$ is marginal in English before constructions; cf. (1a). The temporal shifter will is in a way an open version of the covert FUT in

(34). Perhaps the conventionalized covert construction blocks the overt one.

\subsection{Embedded Perfect: An Ambiguity}

We note that English, like German and French, may use a perfect in the adjunct:

(36) John will leave before Mary has sung.

According to our informants, the sentence is ambiguous; the leaving is either right before the start or before the end of the singing. How can we derive this ambiguity between the before- 
start reading and before-stop reading?

It is often claimed that the Perfect, i.e. have, may bring us to the post time of an event; cf. (Klein, 1994). We may think of have as an operator that converts the property Mary sing into Mary have sung. While Mary sing is an activity, Mary have sung is a state. If a time has the property Mary have sung, any time thereafter has that property as well. This is not the case for the property Mary sing, which is lost after each singing. The following figure illustrates how the ambiguity will be resolved

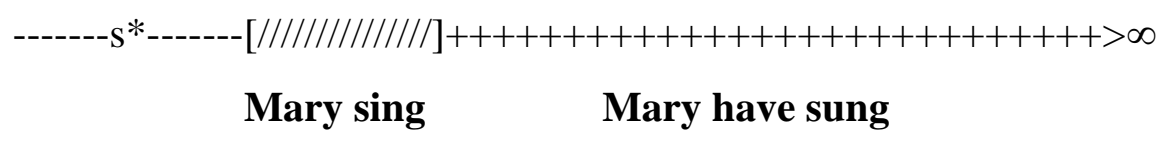

The slash-interval is the running time of Mary sing, the plus-interval is the running time of Mary have sung. Locating John leave before the earliest time of Mary sing gives us the before-start reading, whereas locating John leave before the earliest time of Mary have sung gives us the before-stop reading.

Here is the compositional account of the ambiguity.

Before-start reading:

$\mathrm{n} \lambda_{1}$ woll $\left(\mathrm{t}_{1}\right) \lambda_{2}$ John leave $\left(\mathrm{t}_{2}\right) \&$

$$
\begin{aligned}
& \mathrm{t}_{2} \text { before EARLIEST } \mathrm{WH}_{3} \underline{\mathrm{FUT}}\left(\mathrm{Tpro}_{2}\right) \lambda_{4} \text { have }\left(\mathrm{t}_{4}\right) \lambda_{6}\left[\lambda_{5} \text { Mary } \operatorname{sing}\left(\mathrm{t}_{5}\right)\right. \text { AT } \\
& \left.t_{3}\right]\left(t_{6}\right) \\
& =\left(\exists \mathrm{t}_{2}>\mathrm{s}^{*}\right) \text { John leave }\left(\mathrm{t}_{2}\right) \& \mathrm{t}_{2}<\text { the earliest time } \mathrm{t}_{3} .\left(\exists \mathrm{t}_{4}>\mathrm{t}_{2}\right)\left(\exists \mathrm{t}_{5}<\mathrm{t}_{4}\right) \operatorname{Mary} \operatorname{sing}\left(\mathrm{t}_{5}\right) \\
& \& \underline{\mathrm{t}}_{5}=\mathrm{t}_{3}
\end{aligned}
$$

This construal is conceptually rather odd because the embedded have doesn't really contribute to the meaning. Presumably this reading is hard to get.

$$
\begin{aligned}
& \text { Before-stop reading: } \\
& \mathrm{n} \lambda_{1} \text { woll }\left(\mathrm{t}_{1}\right) \lambda_{2} \text { John leave }\left(\mathrm{t}_{2}\right) \& \\
& \quad \mathrm{t}_{2} \text { before EARLIEST WH} \mathrm{W}_{3} \underline{\operatorname{FUT}}\left(\operatorname{Tpro}_{2}\right)\left[\lambda_{4}\left[\text { have }\left(\mathrm{t}_{4}\right) \lambda_{5} \operatorname{Mary} \operatorname{sing}\left(\mathrm{t}_{5}\right)\right] \text { AT } \mathrm{t}_{3}\right] \\
& =\left(\exists \mathrm{t}_{2}>\mathrm{s}^{*}\right) \text { John leave }\left(\mathrm{t}_{2}\right) \& \mathrm{t}_{2}<\text { the earliest time } \mathrm{t}_{3} .\left(\exists \mathrm{t}_{4}>\mathrm{t}_{2}\right)\left(\exists \mathrm{t}_{5}<\mathrm{t}_{4}\right) \text { Mary } \\
& \operatorname{sing}\left(\mathrm{t}_{5}\right) \& \underline{\mathrm{t}}_{4}=\mathrm{t}_{\underline{3}}
\end{aligned}
$$

In both LFs, the [u-pres] feature of the embedded have comes from the matrix $n$ via woll and $\mathrm{Tpro}_{2}$. The second LF looks complicated as well, but the computation is intuitively easier, because have is incorporated into the VP and what is localized is a state. We think that this is the prevalent reading. The difference between the two structures is that the AT- 
PP modifies the activity Mary sing in the first case whereas it modifies the state have Mary sing in the second structure.

Similarly, we predict an after-startlafter-end ambiguity:

(40) John left after Mary had sung

To our knowledge these ambiguities have not been discussed in the literature. $\mathrm{B} \& \mathrm{C}$ consider only simple states. For these our account gives the same results.

\subsection{Summary for English}

1. before and after are relations between times of type i(it). 2. The complement of the preposition is made up by the definite operator EARLIEST of type (it)i and a temporal relative clause of type (it). 3. The licensing of NPIs under before but not under after follows directly from the meaning of EARLIEST and the prepositions. 4. The non-veridicality of before-adjuncts is derived by assuming a covert modal under before. 5 . The Geis-ambiguity is derived by moving the temporal relative pronoun WH out of a higher or a lower AT-PP. 6 . There are two strategies for the interpretation of the Tense in the adjunct clause, the deictic and the anaphoric construal. 6A. In the deictic construal, the main clause and adjunct clause have in principle the same semantic tense; the identity is concealed by the fact that English and some other languages use a covert FUT in the adjunct if the main clause contains woll; semantically, woll(n) and FUT(n) are identical. 6B. In the anaphoric construal, the adjunct tense is $\mathrm{Tpro}_{\mathrm{i}}$ bound by the matrix PAST or by woll in Stump-sentences; this strategy requires a covert relative FUT in before-adjuncts and a covert relative HAVE (or PAST) in afteradjuncts; evidence from German and French suggest that this strategy is preferable.

\section{BEFORE- AND AFTER-ADJUNCTS IN RUSSIAN}

The syntax of Russian overtly expresses the covert ingredients we have assumed for the English complement of before/after, as we see from the glossing:

$$
\text { Vanya uedet }{ }^{\text {fut,pfv }} \text { do togo kak Masha uedet }{ }^{\text {fut,pfv }} \text {. }
$$

John will-leave before that how Mary will-leave

togo "that" is interpreted as (the) EARLIEST (time), kak "how" is the wh-word moved from the embedded sentence. We noticed above that Russian exhibits a sort of tense harmony: the matrix and adjunct clause have the same tense. The simplest analysis is to assume a deictic tense in the TAC. Here is the analysis of (41): 


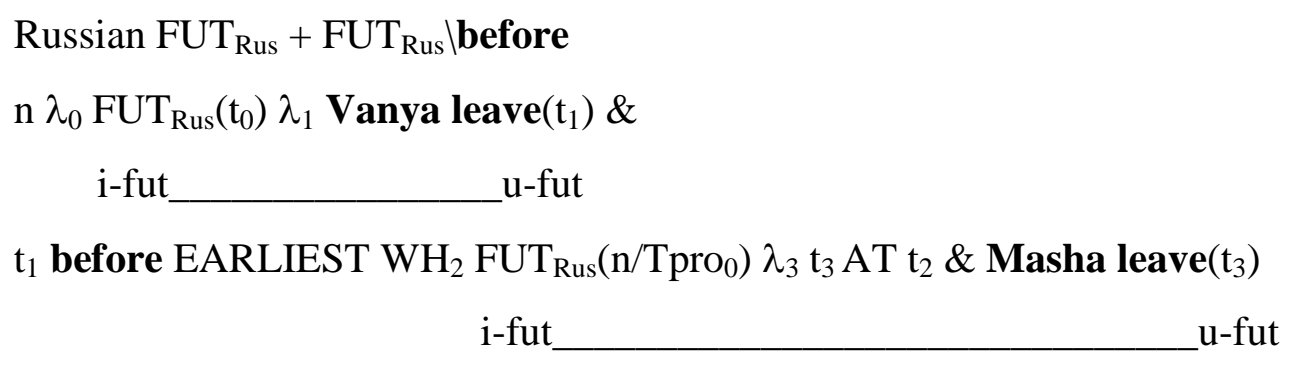

(If the adjunct is non-veridical, we need a silent COULD under EARLIEST.) Remember that unlike English, Russian has a synthetic (morphological) future $\mathrm{FUT}_{\text {Rus }}$ with the feature [i-fut]. We obtain a correct reading also if we replace before with after, i.e., FUT $_{\text {Rus }}+$ FUT $_{\text {Rus }}$ lafter. The lesson we learn from Russian seems to be that the main tense and adjunct tense are the same, when the adjunct tense is deictic.

Note that Russian doesn't allow the insertion of a featureless FUT. Russian has to use either the synthetic future or the temporal auxiliary budet (will) in adjuncts where English highly prefers the present (Grønn and von Stechow, 2011). Here is an example where budet is required both in the matrix and adjunct:

(43) Vanja budet v Moskve do/posle togo kak Masha budet v Moskve.

Vanja will-be in Moscow before/after that how Masha will-be in Moscow

There are cases where the subordinate tense is not the same as in the main clause, cf. the following modalized before-construction with FutlPast:

(44) Svad'ba dolzhna ${ }^{\text {modal }}$ byla ${ }^{\text {past }}$ sostojat'sja v mae, do togo kak karbasy ujdut ${ }^{\text {fut,pvf }}$ na jug.

wedding necessary was take-place in May, before that how boats will-go toward south

'The wedding would take place in May, before the cargo boats headed south' (The RuN parallel corpus)

It is not possible to interpret the embedded $\mathrm{FUT}_{\text {Rus }}$ deictically because the departure of the boats might occur before the speech time. So in the adjunct we need Tpro by the TPRO under the modal dolzhna ('necessary'). This is the construal we expect for constructions embedded under modals or attitudes.

\section{BEFORE- AND AFTER-ADJUNCTS IN JAPANESE}

In Japanese we always have Pastlafter and Preslbefore; cf. (5 a/b). This distribution has 
puzzled semanticists for decades. We start the discussion with Kusumoto's observation that no ambiguity arises in Geis' sentences. Only the upper construal exists (Kusumoto, 1999), chap. 3, p.213:

$$
\begin{aligned}
& \text { Junko-wa [[[zibun-ga kaeru to] } \left.\left.\text { itta }^{\text {past }}\right] \text { atode }\right] \text { kaetta }^{\text {past }} \\
& \text { J-top [[[self leave comp] say] after] leave } \\
& \text { 'Junko left after she said she would' }
\end{aligned}
$$

Kusumoto concludes that no wh-movement of the temporal relative pronoun can be involved in this construction. Following (Arregui and Kusumoto, 1998) she proposes that Japanese temporal propositions maeni/atode select a TP unlike English before/after, which select a CP. To make the proposal consistent with the present approach, we have to say that EARLIEST embeds a CP in English-like languages, but a TP in Japanese.

The standard assumption in Generative Grammar is that the landing site of a whphrase is SpecCP. A TP lacks that position and therefore can't host a moved wh-pronoun, regardless of whether it comes from the lower AT-PP or from the higher one. Still, Kusumoto has to account for the fact that the adjunct in (45) means the same as the higher construal in English.

To make sure that EARLIEST (in Kusumoto's approach before/after) embeds a temporal property of type (it) without a moved wh-word, Kusumoto leaves the time variable of the adjunct tense unsaturated. In our approach, the time argument always comes first, so it seems that we have to saturate it in the LF syntax. But recall that we can have TPRO as the Tcentre. At LF, TPRO is moved. Look now at an expression of the form [TPRO $\left.\lambda_{i} \operatorname{PAST}\left(t_{i}\right) P\right]$. It has the type (it), and the semantic tense may be regarded as having an unsaturated time variable.

Recall from Part 1 that we assume a relative semantic Present (non-Past) for Japanese:

$$
\text { [ } \mathrm{PRES}_{\text {Jap }} \rrbracket=\lambda \mathrm{w} \lambda \mathrm{t} \lambda \mathrm{P}_{\mathrm{it}} .\left(\exists \mathrm{t}^{\prime} \neg<\mathrm{t}\right) \mathrm{P}\left(\mathrm{t}^{\prime}\right) \text {, where } \mathrm{t}^{\prime} \neg<\mathrm{t} \text { iff no part of } \mathrm{t}^{\prime} \text { is before } \mathrm{t} \text {. }
$$
feature: [i-pres]

The Geis sentence in (45) is now analyzed as follows:

$$
\mathrm{n} \lambda_{1} \operatorname{PAST}\left(\mathrm{t}_{1}\right) \lambda_{2} \text { Junko leave }\left(\mathrm{t}_{2}\right) \& \mathrm{t}_{2} \text { after EARLIEST }
$$




$$
\begin{aligned}
& \text { [те TPRO } \left.\lambda_{3} \operatorname{PAST}\left(\mathrm{t}_{3}\right) \lambda_{4} \operatorname{Junko} \operatorname{say}\left(\mathrm{t}_{4}\right)\left[\text { [сР TPRO } \lambda_{5} \operatorname{PRES}_{\mathrm{J}}\left(\mathrm{t}_{5}\right) \lambda_{6} \operatorname{she~leave}\left(\mathrm{t}_{6}\right)\right]\right] \\
& \text { i-past_u-past_u-pres___ u-pres }
\end{aligned}
$$

$=\lambda \mathrm{w}\left(\exists \mathrm{t}_{2}<\mathrm{s}^{*}\right)$ Junko leave $\mathrm{w}_{\mathrm{w}}\left(\mathrm{t}_{2}\right) \& \mathrm{t}_{2}>$

the earliest $\mathrm{t}_{3} \cdot\left(\exists \mathrm{t}_{4}<\mathrm{t}_{3}\right)$ Junko say $_{\mathrm{w}}\left(\mathrm{t}_{4}\right) \lambda \mathrm{w}^{\prime} \lambda \mathrm{t}_{5} \cdot\left(\exists \mathrm{t}_{6} \neg<\mathrm{t}_{5}\right)$ she leave $\mathrm{w},\left(\mathrm{t}_{6}\right)$

No ambiguity can arise on this analysis.

Here is the analysis of (5a), respecting the Japanese word order:

[Junko-ga kuru ${ }^{\text {pres }}$ maeni] Satoshi-wa kaetta ${ }^{\text {past }}$

[[Junko come] before] Satoshi leave

[TP PAST(n) $\lambda_{1}\left[\right.$ AdvP [EARLIEST [те TPRO $\lambda_{2}$ PRES $_{\text {Jap }}\left(t_{2}\right) \lambda_{3} \mathbf{J}$. come $\left.\left.\left(t_{3}\right)\right]\right]$ before] i-pres u-pres

\section{S. leave $\left.\left(\mathrm{t}_{1}\right)\right]$}

$=\left(\exists \mathrm{t}_{1}<\mathrm{s}^{*}\right)$ Satoshi leave $\left(\mathrm{t}_{1}\right) \& \mathrm{t}_{1}<$ the earliest $\mathrm{t}_{2} .\left(\exists \mathrm{t}_{3}\right)\left[\mathrm{t}_{3} \neg<\mathrm{t}_{2} \&\right.$ Junko come $\left.\left(\mathrm{t}_{3}\right)\right]$

The remaining combinations Pres + Preslbefore, Past + Pastlafter and Pres + Pastlafter are analyzed along the same lines.

The acute reader may have noticed that the truth-condition of the LF in (48) is not consistent: the earliest time $t_{2}$ such that $t_{3}$ does not precede it, is the beginning of the time axis. But then there can't be a time $t_{1}$ before $t_{2}$. The inconsistency is due to our analysis of PRES $_{\text {Jap }}$ as non-Past. (Ogihara, 1996) assumes correctly that PRES Future (>) and Identity (=). In our example, the meaning has to be identity, but in other contexts the Japanese non-Past can be a Future. We think that it is a matter of pragmatics to choose the correct meaning. For convenience, we keep the notation $\neg<$.

Kusumoto (p. 218) expresses some doubts about whether an approach along these lines can explain the tense under beforelafter. Why don't we have Pastlbefore? In fact, there is nothing in the theory that rules out this construction. A closer inspection reveals, however, that Pastlbefore would give us an extremely weak reading for states. Think of the sentence Cleo was in the US before David was as if it were Japanese and assume that the semantic tense in the adjunct is PAST:

$$
\begin{aligned}
& \operatorname{PAST}(\mathrm{n}) \lambda_{1} \text { Cleo be }\left(\mathrm{t}_{1}\right) \text { in the US \& } \\
& \mathrm{t}_{1} \text { before EARLIEST TPRO } \lambda_{2} \operatorname{PAST}\left(\mathrm{t}_{2}\right) \lambda_{3} \text { David be }\left(\mathrm{t}_{3}\right) \text { in the US } \\
& \left(\exists \mathrm{t}_{1}<\mathrm{s}^{*}\right) \text { C. be }\left(\mathrm{t}_{1}\right) \text { in the US \& } \mathrm{t}_{1}<\text { the earliest } \mathrm{t}_{2} \cdot\left(\exists \mathrm{t}_{3}<\mathrm{t}_{2}\right) \mathrm{D} \text {. be }\left(\mathrm{t}_{3}\right) \text { in the US }
\end{aligned}
$$

The meaning of the sentence is compatible with a scenario in which Cleo and David arrived 
at the same time in the US. Clearly it is highly misleading to use the sentence for that scenario. Exactly the same point can be made for PRES Jlafter. So Pastlbefore and Preslafter are pragmatically blocked. Kusumoto's account therefore explains the distribution despite her scepticism. Note that the problem does not arise for English, where we can have a deictic Tense in the TAC.

Summary for Japanese. To explain the Presentlbefore and Pastlafter selection, we assume with Kusumoto that these prepositions select a TP (via EARLIEST). The adjunct tense is then centred around TPRO and there is no temporal wh-pronoun in the adjunct; in other words, Japanese before/after adjuncts are semantically tenseless. The combinations Pastlbefore and Presentlafter are blocked pragmatically.

\section{WHEN-ADJUNCTS}

\subsection{English}

Recall that we find Stump-sentences in English when-adjuncts: Presentlwill. Another puzzling fact is that the temporal relation between the two events involved appears to be not uniform:
a. John arrived when Mary was asleep. (overlap)
b. Mary was asleep when John arrived. (overlap)

When John broke his leg, he also hurt is elbow. (simultaneous)

a. When John wrecked the car, Bill fixed it. (adjunct event before matrix)

b. When Lindberg crossed the Atlantic, he chose Long Island as his starting point. (matrix event before adjunct) (Stump, 1985), p. $153 \mathrm{f}$.

For when-adjuncts we observe Geis' ambiguity:

$$
\text { Olga left when Harry told her to leave. (ambiguous) }
$$

Nevertheless, following a proposal of (Arregui and Kusumoto, 1998, Kusumoto, 1999), according to which when is the temporal relative pronoun, the analysis of when-adjuncts is surprisingly simple; when, like any other relative pronoun, is semantically vacuous. Our LF for the sentence in (50a) is this:

(54) $\operatorname{PAST}(\mathrm{n}) \lambda_{2}\left[\left[\right.\right.$ John arrive $\left.\left(\mathrm{t}_{2}\right)\right] \&\left[{ }_{\mathrm{RC}}\right.$ when $\lambda_{4} \operatorname{PAST}(\mathrm{n}) \lambda_{5}\left[\right.$ Mary be $\left(\mathrm{t}_{5}\right)$ asleep $\& \mathrm{t}_{5}$ $\left.\left.\left.\mathrm{AT}_{4}\right]\right]\right]\left(\mathrm{t}_{2}\right)$ 


$$
\begin{aligned}
& =\operatorname{PAST}(n) \lambda_{2}\left[\text { John arrive }\left(t_{2}\right) \& \operatorname{PAST}(n)\left[\lambda_{5} \text { Mary be }\left(t_{5}\right) \text { asleep } \& t_{5} \text { AT } t_{2}\right]\right] \\
& \text { (by } \lambda \text {-conversion) } \\
& =\left(\exists \mathrm{t}_{2}<\mathrm{s}^{*}\right)\left[\mathrm{John} \operatorname{arrived}\left(\mathrm{t}_{2}\right) \&\left(\exists \mathrm{t}_{5}<\mathrm{s}^{*}\right) \text { Mary was }\left(\mathrm{t}_{5}\right) \text { asleep } \& \mathrm{t}_{5}=\mathrm{t}_{2}\right] \\
& \text { (simplification) } \\
& =\left(\exists \mathrm{t}_{2}<\mathrm{s}^{*}\right)\left[\mathrm{John} \operatorname{arrived}\left(\mathrm{t}_{2}\right) \& \operatorname{Mary} \text { was }\left(\mathrm{t}_{2}\right)\right. \text { asleep] }
\end{aligned}
$$

The simplified truth-condition shows that the main verb and the verb in the adjunct are evaluated at the same past time. Therefore the adjunct is interpreted as if it were tenseless. The last mentioned fact gives us the key for the treatment of Stump's pattern in (6a). A deictic present in the adjunct would yield an inconsistent interpretation, so the Present in the adjunct must be a Tpro ${ }_{i}$ bound by will:

$$
\begin{aligned}
& \mathrm{n} \quad \lambda_{1} \operatorname{woll}\left(\mathrm{t}_{1}\right) \lambda_{2} \text { John leave }\left(\mathrm{t}_{2}\right) \&\left[\text { when }_{3} \operatorname{Tpro}_{2} \lambda_{4} \operatorname{Mary} \operatorname{sing}\left(\mathrm{t}_{4}\right) \& \mathrm{t}_{4} \mathrm{AT} \mathrm{t}_{3}\right]\left(\mathrm{t}_{2}\right) \\
& \text { i-pres___u-pres____ u-pres___ u-pres___ u-pres } \\
& \text { i-inf__ u-inf } \\
& =\mathrm{n} \lambda_{1} \text { woll }\left(\mathrm{t}_{1}\right) \lambda_{2} \text { John leave }\left(\mathrm{t}_{2}\right) \& \mathrm{Tpro}_{2} \lambda_{4} \operatorname{Mary} \operatorname{sing}\left(\mathrm{t}_{4}\right) \& \mathrm{t}_{4} \mathrm{AT} \mathrm{t}_{2}
\end{aligned}
$$

(by $\lambda$-conversion)

$=\mathrm{n} \lambda_{1} \operatorname{woll}\left(\mathrm{t}_{1}\right) \lambda_{2}$ John leave $\left(\mathrm{t}_{2}\right) \&$ Mary $\operatorname{sing}\left(\mathrm{t}_{2}\right)(\lambda$-conversion and simplification $)$

Let us first comment on the licensing of the present tense. English is an SOT language. Therefore woll transmits [u-pres] to the bound variables $\mathrm{t}_{2}$ and $\mathrm{Tpro}_{2}$. Tpro 2 transmits $[\mathrm{u}-$ pres] to the time variable $\mathrm{t}_{4}$ of sing. [u-pres] is pronounced at $\mathrm{PF}$ as will and sings. Recall form Part 1 that woll transmits the status feature [u-inf] to leave determining its pronunciation as an infinitive. In order to block the further transmission of $\left[\mathrm{u}\right.$-inf] to $\mathrm{Tpro}_{2}$, and ultimately to $t_{4}$, we have to stipulate that status features with the u-prefix are not transmitted by binding, i.e. [i-inf] only goes to the verb that is directly subcategorized by woll. The $\lambda$-reduction of the LF in (55) makes it clear that the when-adjunct is semantically tenseless when it contains an anaphoric T-centre that is bound by a higher T-shifter.

Note that the system allows us to have will under a deictic Present in the adjunct. Whatever blocks a deictic will in before/after-adjuncts also blocks will in when-adjuncts.

The Geis-ambiguity is analyzed as in before/after-adjuncts. For instance, the lower construal of (53) is this:

$$
\begin{aligned}
& \operatorname{PAST}(\mathrm{n}) \lambda_{1} \text { Olga leave }\left(\mathrm{t}_{1}\right) \&\left[\text { when }_{2} \operatorname{PAST}(\mathrm{n}) \lambda_{3} \text { Harry tell }\left(\mathrm{t}_{3}\right) \text { her } \lambda_{4}\right. \text { PRO to } \\
& \left.\operatorname{leave}\left(\mathrm{t}_{4}\right) \& \mathrm{t}_{4} \text { AT } \mathrm{t}_{2}\right]\left(\mathrm{t}_{1}\right)
\end{aligned}
$$




$$
\begin{aligned}
= & \lambda \mathrm{w} \cdot\left(\exists \mathrm{t}_{1}<\mathrm{s}^{*}\right) \text { Olga leave } \mathrm{w}_{\mathrm{w}}\left(\mathrm{t}_{1}\right) \&\left(\exists \mathrm{t}_{3}<\mathrm{s}^{*}\right)\left[\text { Harry tell } \mathrm{w}_{\mathrm{w}}\left(\mathrm{t}_{3}\right) \text { her } \lambda \mathrm{w}^{\prime} \lambda \mathrm{t}_{4}\right. \text { PRO to } \\
& \text { leave } \left.\left(\mathrm{t}_{4}\right) \& \mathrm{t}_{4}=\mathrm{t}_{1}\right]
\end{aligned}
$$

Let us say a few words about the temporal ordering of the events. We think that the account of (52a) requires the silent introduction of an "and next"; cf. (Partee, 1984) for similar cases of "narrative progression". We can identify this pragmatic operator with a covert FUT. The semantic tense in the adjunct is interpreted most smoothly as Tpro ${ }_{i}$ bound by the matrix tense:

$$
\begin{aligned}
& \operatorname{PAST}(n) \lambda_{2}\left[\left[{ }_{R C} \text { when }_{3} \operatorname{Tpro}_{2} \lambda_{4} \operatorname{John} \text { wreck }\left(t_{4}\right) \text { his car } \& t_{4} A T t_{3}\right]\left(t_{2}\right)\right. \\
& \text { i-past_u_past_u-past u u u } \\
& \left.\& \lambda_{5}\left[\underline{\mathrm{FUT}}\left(\mathrm{t}_{5}\right) \lambda_{6} \operatorname{Bill} \text { fix }\left(\mathrm{t}_{6}\right) \text { it }\right]\left(\mathrm{t}_{2}\right)\right] \\
& \text { u-past__u-past } \\
& =\left(\exists \mathrm{t}_{2}<\mathrm{s} *\right) \text { John wreck his car at } \mathrm{t}_{2} \&\left(\exists \mathrm{t}_{7}>\mathrm{t}_{2}\right) \text { Bill fix it at } \mathrm{t}_{7}
\end{aligned}
$$

(52b) is analyzed in a similar way, but we have to assume a silent PAST above the main verb. In other words, the sentence is interpreted as if it were When Lindberg crossed the Atlantic, he had started in Long Island.

$$
\begin{aligned}
& \text { PAST(n) } \lambda_{2}\left[\left[{ }_{R C}\right.\right. \text { when } \\
& \left.3 \operatorname{Tpro}_{2} \lambda_{4} \text { Lindberg cross }\left(t_{4}\right) \text { the Atlantic } \& t_{4} A_{T} t_{3}\right]\left(t_{2}\right) \\
& \left.\& \lambda_{5}\left[\operatorname{PAST}\left(t_{5}\right) \lambda_{6} \text { he } \operatorname{start}\left(t_{6}\right) \text { in Long Island }\right]\left(t_{2}\right)\right]
\end{aligned}
$$

Thus, the intersective analysis of when-adjuncts as relative clauses gives us a lot of flexibility for dealing with different temporal orderings between the two events involved.

Summary. Given that when is a temporal relative pronoun, the when-clause is simultaneous with the main clause. The Stump paradigm - Presentlwill - follows from the account if we assume that the T-centre of the adjunct is $\mathrm{Tpro}_{\mathrm{i}}$ bound by the matrix Tense. If the two events are not interpreted simultaneously, we pragmatically adjust the temporal order of the two conjuncts.

\subsection{Russian}

As usual, the adjunct tense of Russian is independent from the main tense. Here is the analysis of (7).

$$
\begin{aligned}
& \mathrm{FUT}_{\text {Rus }}(\mathrm{n}) \lambda_{2} \text { Alla leave }\left(\mathrm{t}_{2}\right) \&\left[\text { when }_{3} \mathrm{FUT}_{\text {Rus }}(\mathrm{n}) \lambda_{4} \operatorname{Vova} \text { leave }\left(\mathrm{t}_{4}\right) \& \mathrm{t}_{4} \mathrm{AT} \mathrm{t}_{3}\right]\left(\mathrm{t}_{2}\right) \\
& \text { i-fut_u-fut i-fut_u-fut } \\
& \left(\exists \mathrm{t}_{2}>\mathrm{s}^{*}\right) \text { Alla leave }\left(\mathrm{t}_{2}\right) \&\left(\exists \mathrm{t}_{4}>\mathrm{s}^{*}\right) \operatorname{Vova} \text { leave }\left(\mathrm{t}_{4}\right) \& \mathrm{t}_{4}=\mathrm{t}_{2}
\end{aligned}
$$

Recall that Russian has a synthetic future that determines the morphology of the verb. The 
PastlPast configuration is treated alike.

The SOT-parameter predicts that we can't have a Stump configuration, i.e. a dependent (non-deictic) Presentlbudet (= woll) in Russian, instead we get budetlbudet:

Alla budet ${ }^{\text {pres }}$ rabotat', kogda Vova budet ${ }^{\text {pres }}$ rabotat'

Alla woll work when Vova woll work

Thus the Russian temporal organization is as simple as it can possibly be.

\subsection{Japanese}

Unlike English and Russian, Japanese has Past \Past or Pres\Past in when-constructions; cf. (8) and (9) above. Unlike beforelafter-adjuncts, Japanese when-adjuncts exhibit an ambiguity in the Geis constellation.

PastlPast is analyzed as in Russian, while Pres\Past follows directly from the assumption that Japanese has a relative Present (non-Past). Recall that Russian doesn't have that Tense in our theory and therefore lacks this construction. Here is the LF for the Pres $\backslash$ Past configuration in (9), respecting the Japanese word order. $\left(\mathrm{pro}_{\mathrm{i}}\right.$ stands for the empty subject in the RC, which denotes "I" in the example.)

$$
\begin{aligned}
& \operatorname{PAST}(\mathrm{n}) \lambda_{1}\left[\left[_{\mathrm{RC}}\left[\mathrm{PRES}_{\mathrm{Jap}}\left(\mathrm{Tpro}_{1}\right) \lambda_{3} \mathrm{t}_{3} \mathrm{AT}_{2} \& \operatorname{pro}_{\mathrm{i}} \text { sleep-be }\left(\mathrm{t}_{3}\right)\right] \mathbf{w h e n}_{2}\right]\left(\mathrm{t}_{1}\right) \&\right. \\
& \text { i-past i-pres_u-pres } \\
& \text { Junko come } \left.\left(\mathrm{t}_{1}\right)\right] \\
& \text { u-past } \\
& \left(\exists \mathrm{t}_{1}<\mathrm{s} *\right)\left[\text { Junko come }\left(\mathrm{t}_{1}\right) \&\left(\exists \mathrm{t}_{3} \neg<\mathrm{t}_{1}\right) \mathrm{t}_{3}=\mathrm{t}_{1} \& \text { pro } \text { i }_{\mathrm{i}} \text { sleep }\left(\mathrm{t}_{3}\right)\right]
\end{aligned}
$$

Importantly, the semantic tense in the adjunct is a Tpro ${ }_{i}$ bound by the matrix PAST. Obviously the embedded PRES ${ }_{\text {Jap }}$ cannot be deictic. Here it is interpreted as simultaneity.

Next, we look at the Geis sentences:

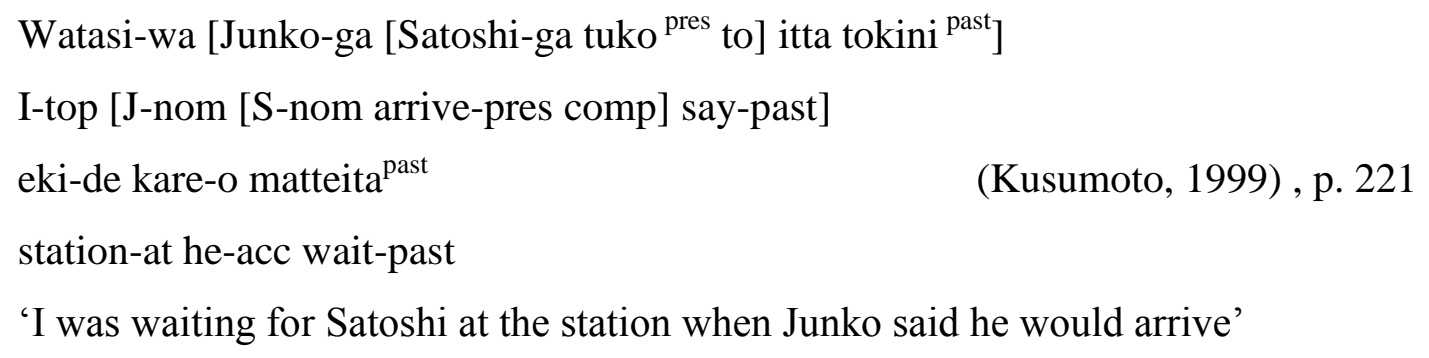

Kusumoto writes that the sentence can mean that I was waiting at the time of Junko's 
utterance or, more naturally, at the time according to which Satoshi was supposed to arrive. Here is the LF for the lower construal:

$$
\begin{aligned}
& \mathrm{n} \lambda_{1} \operatorname{PAST}\left(\mathrm{t}_{1}\right) \lambda_{2}\left[\mathbf { I } \text { be-waiting } ( \mathrm { t } _ { 2 } ) \text { at the station } \& \left[\mathbf{w h e n}_{3} \operatorname{PAST}\left(\mathrm{Tpro}_{2}\right) \lambda_{4}\right.\right. \text { Junko } \\
& \left.\operatorname{say}\left(\mathrm{t}_{4}\right) \text { TPRO } \lambda_{5} \operatorname{PRES}_{\text {Jap }}\left(\mathrm{t}_{5}\right) \lambda_{6} \mathrm{t}_{6} \mathrm{AT} \mathrm{t}_{3} \&\left(\text { he) } \operatorname{arrives}\left(\mathrm{t}_{6}\right)\right]\left(\mathrm{t}_{2}\right)\right] \\
& \text { i-pres } \\
& \text { u-pres } \\
& \lambda \mathrm{w} .\left(\exists \mathrm{t}_{2}<\mathrm{s}^{*}\right)\left[\mathrm { I } \mathrm { wait } _ { \mathrm { w } } ( \mathrm { t } _ { 2 } ) \& ( \exists \mathrm { t } _ { 4 } < \mathrm { t } _ { 2 } ) \left[\mathrm { J } \cdot \mathrm { say } _ { \mathrm { w } } ( \mathrm { t } _ { 4 } ) \lambda \mathrm { w } ^ { \prime } \lambda \mathrm { t } _ { 5 } \cdot ( \exists \mathrm { t } _ { 6 } \neg < \mathrm { t } _ { 5 } ) \left[\mathrm{t}_{6}=\mathrm{t}_{2} \& \mathrm{~S}\right.\right.\right. \text {. } \\
& \left.\left.\left.\operatorname{arrive}_{\mathrm{w}},\left(\mathrm{t}_{6}\right)\right]\right]\right]
\end{aligned}
$$

None of the embedded tenses are deictic. PAST(Tpro 2$)$ is bound by the higher deictic $\operatorname{PAST}(\mathrm{n})$ and has the effect that the saying must be before the waiting. The relative PRES Jap in the complement of say locates the time of the expected arrival after the subjective time of the saying, and the (relativized) AT-PP identifies the expected time with the time of the waiting.

\subsection{Wh-Agreement in German}

German gives further evidence that Arregui \& Kusumoto's analysis of when as a temporal relative pronoun is correct. German has two variants of when, viz wenn and als. als is restricted to a past tense (Preterit or Perfect); wenn is restricted to the Present.

(64) Hans kommt, ${ }^{\mathrm{OK}}$ wenn/*als Maria geht.

Hans comes when Mary leaves

(65) Hans kam/ist gekommen *wenn/ ${ }^{\mathrm{OK}}$ als Maria ging/gegangen ist.

Hans came/is come when Mary went/gone is

We think of this as a special case of the German rule of RC agreement. The German relative pronoun agrees in number and gender with the head noun:
a. die Frau ${ }^{\text {fem }}$, die $^{\text {fem }}$ ich liebe the woman ${ }^{\text {fem }}$ that $^{\text {fem }}$ I love
b. der Mann ${ }^{\text {male }}$, den ${ }^{\text {male }}$ ich kenne the man ${ }^{\text {male }}$ that ${ }^{\text {male }}$ I know

The when-adjunct modifies a VP and the relative pronoun agrees with the head of the VP, the verb with a temporal feature.

$$
\text { a. [vp Hans kommt }{ }^{\text {pres }} \text { [ [wenn }{ }^{\text {pres }} \text { Maria geht] }
$$



b. [vP Hans kam ${ }^{\text {past }}$ [als ${ }^{\text {past }}$ Maria ging]
c. [vp Hans gekommen ${ }^{\text {past.pp }}$ [als ${ }^{\text {past }}$ Maria ging]

A closer inspection would reveal that this feature agreement comes from the semantic tense that licenses the morphological tense of the verb. We leave it open how this agreement process is formulated exactly.

\section{CONCLUSION FOR TACS}

1. English TAC Tense is bound in Pres/woll-constructions, in other constructions it is deictic. Tense licensing is non-local in bound constructions. In deictic constructions it is local.

2. Russian TAC Tense is deictic. Tense licensing is local.

3. Japanese TAC Tense is bound. In before/after-adjuncts the T-centre is TPRO, in when-clauses the T-centre is Tpro . Tense licensing is local.

The SOT-parameter is relevant only for the English Preslwoll-construction.

Under an attitude or a modal, the higher Present $n$ will be replaced by TPRO, and the TAC Tense has a Tpro ${ }_{i}$ as centre, where Tpro is bound by TPRO.

\section{COMMENTS ON THE LITERATURE}

The starting point for a compositional analysis of TACs is (Heinämäki, 1974). She analyzes temporal conjunctions as two-place quantifiers. One drawback of the account is that it is not clear how tense can be integrated because the connectives are of type (it)(it,t). Other problems have been discussed in (Stump, 1985).

A significant progress is made in (Stump, 1985). Stump (p. 91) analyzes all the temporal prepositions as existential quantifiers according to the schema $\lambda \mathrm{t} \lambda \mathrm{P}_{\mathrm{it}} . \exists \mathrm{t}_{1}\left[\mathrm{t} \mathrm{R} \mathrm{t}_{1} \&\right.$ $\mathrm{P}\left(\mathrm{t}_{1}\right)$ ], with $\mathrm{R}=$ '=' for when, $\mathrm{R}=$ ' $<$ ' for before, $\mathrm{R}=$ ' >' for after. Stump also discovered the data we referred to as Stump's paradigm. He is not aware of the DE-facts in the scope of before. when is not treated as a wh-word; instead of wh-movement he inserts a covert at-PP and an abstraction rule that does the job of wh-movement; Stump can derive Geis' ambiguities. The Present/will facts are analyzed by assuming a somewhat ad hoc deictic NON-PAST in the adjunct.

(Ogihara, 1996)'s conjunctions have a complicated semantic type. Ogihara's 
integration of Tense is also complicated and cannot be discussed here. Ogihara is the first to give a formal analysis of Japanese before/after-adjuncts. He can explain the Pastlafter and Preslbefore by showing that the illicit combinations lead to inconsistencies. He assumes a relative Present $($ ambiguous between $=$ and $>$ ). Ogihara speculates that the English Pres|will data can be explained by an obligatory application of the SOT rule. There are, however, some unexplained residua; therefore he doesn't commit himself to a final analysis of English.

(Kusumoto, 1999) extends the analysis to Polish and Russian. Our analysis of Russian before/after-adjuncts is compatible with her work. (Arregui and Kusumoto, 1998, Kusumoto, 1999) explain the missing Geis-ambiguity in Japanese by the stipulation, which we adopt, that Japanese before/after embed a TP. Kusumoto doesn't have the EARLIEST-operator. before/after are generalized temporal quantifiers, where before imposes a modalization of the first argument (cf. pp. 203 and 212 (Kusumoto, 1999)). Finally, Kusumoto has no relative Present but analyzes present verbs as tenseless (cf. our criticism in Part 1). We don't adopt Kusumoto's tenseless RCs for Japanese but follow Ogihara on this point.

The essential step to our understanding of when-adjuncts is due to (Arregui and Kusumoto, 1998); in earlier work, when was analyzed as a conjunction. We think that the analysis as a relative pronoun is the most revealing one.

Further important progress was made with the introduction of the EARLIEST-operator (Beaver and Condoravdi, 2003) which allows a unified account of the prepositions before/after and matches the Russian surface syntax.

Temporal adjuncts need a silent AT-PP in the composition, as observed already in (Dowty, 1979). An overt at is folklore in the tense literature.

The theory of tense licensing via feature transmission under binding is our own. Alternative approaches are possible, such as the structural licensing approach of Kusumoto.

\section{LITERATURE}

Anscombe, G.E.M. 1964. Before and after. The Philosophical Review 74:3-24.

Arregui, Ana, and Kusumoto, Kiyomi. 1998. Tense in Temporal Adjunct Clauses. Paper presented at SALT VII, Cornell University, Ithaca, N.Y.

Beaver, David, and Condoravdi, Cleo. 2003. A Uniform Analysis of "before" and "after". Paper presented at Proceedings of SALT 13, Cornell, Ithaca.

Dowty, David. 1979. Word Meaning and Montague Grammar: the semantics of verbs and times in generative semantics and in Montague's PTQ: Synthese Language Library. Dordrecht: Reidel.

Geis, Michael. 1970. Adverbial Subordinate Clauses in English, MIT: Ph.D. dissertation. 
Grønn, Atle, and von Stechow, Arnim. 2011. Future vs. Present in Russian and English Adjunct Clauses. Scando-Slavica Tomus 57:2:245-267.

Heinämäki, Orvokki Tellervo. 1974. Semantics of English Temporal Connectives, University of Texas at Austin: PhD Dissertation.

Klein, Wolfgang. 1994. Time in Language. London, New York: Routledge.

Kusumoto, Kiyomi. 1999. Tense in embedded contexts, Department of Linguistics, University of Massachusetts at Amherst: Ph.D. dissertation.

Ladusaw, William A. 1979. Polarity Sensitivity as Inherent Scope Relations, The University of Texas at Austin: PhD dissertation, published 1980 by Garland Press, New York.

Ogihara, T. 1996. Tense, Attitudes, and Scope. Dordrecht: Kluwer.

Partee, B. 1984. Nominal and Temporal Anaphora. Linguistics and Philosophy 7:243-286.

Stump, Gregory. 1985. The Semantic Variability of Absolute Constructions: Synthese Language Library. Dordrecht: Reidel.

von Stechow, Arnim. 2002. Temporally Prepositions with Quantifiers: Some Additions to Pratt \& Frances (2001). Linguistics and Philosophy: 48.

von Stechow, Arnim. 2005. Semantisches und morphologisches Tempus: Zur temporalen Orientierung von Einstellungen und Modalen [August 2005]. Neue Beiträge zur Germanistik 4 (2):36. 